\title{
Key Functions and Therapeutic Prospects of Nur77 in Inflammation Related Lung Diseases
}

\author{
Asoka Banno, ${ }^{*}$ Sowmya P. Lakshmi, ${ }^{* \dagger}$ Aravind T. Reddy, ${ }^{{ }^{\dagger}}$ Seong C. Kim, ${ }^{{ }^{\dagger}}$ and Raju C. Reddy ${ }^{{ }^{\dagger}}$
}

From the Division of Pulmonary, Allergy and Critical Care Medicine, * Department of Medicine, University of Pittsburgh School of Medicine, Pittsburgh; and the Veterans Affairs Pittsburgh Healthcare System, ${ }^{\dagger}$ Pittsburgh, Pennsylvania

\author{
Accepted for publication \\ October 4, 2018. \\ Address correspondence to \\ Raju C. Reddy, M.D., Division \\ of Pulmonary, Allergy and \\ Critical Care Medicine, Uni- \\ versity of Pittsburgh School of \\ Medicine, 3459 Fifth Ave., \\ Pittsburgh, PA 15213. E-mail: \\ reddyrc@upmc.edu.
}

\begin{abstract}
The transcription factor Nur77 belongs to the NR4A subfamily of nuclear hormone receptors. It features an atypical ligand-binding site that precludes canonical ligand binding, leading to the designation orphan nuclear receptor. However, recent studies show that small molecules can interact with the receptor and modulate its activity by inducing a conformational change in the Nur77 ligand-binding site. Nur77 expression and activation are rapidly induced by various physiological and pathologic stimuli. Once expressed, Nur77 initiates transcriptional activity and modulates expression of its target genes. Both in vitro and in vivo evidence shows that Nur77 dampens the immune response to proinflammatory stimuli, such as tumor necrosis factor- $\alpha$, Toll-like receptor ligands, and oxidized lipids, primarily by suppressing NF- $\kappa B$ signaling. Although studies focusing on Nur77's role in lung pathophysiology are currently incomplete, available data support its involvement in the pathogenesis of lung diseases, including asthma, acute lung injury, and pulmonary fibrosis, and thus suggest a therapeutic potential for Nur77 activation in these diseases. This review addresses the mechanisms that control Nur77 as well as its known roles in inflammation-related lung diseases. Evidence regarding the therapeutic potential of Nur77-targeting molecules will also be presented. Although current knowledge is limited, additional research followed by clinical studies may firmly identify Nur77 as a pharmacologic target for inflammation-related lung diseases. (Am J Pathol 2019, 189: 482-491; https://doi.org/ 10.1016/j.ajpath.2018.10.002)
\end{abstract}

Nur77 $7^{1,2}$ [alias nuclear receptor subfamily 4 group $\mathrm{A}$ member 1 (NR4A1), NGFI-B, HMR, TR3, N10, NP10, GFRP1, or NAK1] is a transcription factor belonging to the NR4A subfamily of nuclear hormone receptors., ${ }^{3,4}$ Other members of this orphan nuclear receptor subfamily are Nurrelated factor 1 (Nurr1 ${ }^{5}$; alias NR4A2) and neuron-derived orphan receptor 1 (NOR-1 ${ }^{6}$; alias NR4A3). ${ }^{3,4}$ Like classical nuclear hormone receptors, ${ }^{7}$ members of the NR4A subfamily contain a DNA binding domain that is flanked by a transactivation domain on the $\mathrm{N}$-terminus and a ligandbinding domain on the C-terminus. ${ }^{3,4}$ Protein sequences of the DNA- and ligand-binding domains are conserved throughout the NR4A subfamily, with $91 \%$ to $95 \%$ and $58 \%$ to $65 \%$ similarity, respectively. ${ }^{4,8}$ In contrast, these receptors' transactivation domains share only $26 \%$ to $28 \%$ homology. ${ }^{8}$
Notable features of these orphan nuclear receptors are their atypical ligand-binding domains. A crystal structure of the Nurr1 ligand-binding domain displayed a ligand-binding pocket occupied by bulky hydrophobic residues, leading to the assumption that no natural ligand would bind the NR4A receptors. ${ }^{9}$ Consistent with the sequence homology between Nurr1 and Nur77, a later study showed a similar structure for the rat Nur77 ligand-binding domain. ${ }^{10}$ Yet, accumulating evidence shows that small molecules, such as cytosporone $\mathrm{B}^{11}$ and $n$-pentyl 2-[3,5-dihydroxy-2-(1-nonanoyl)phenyl]acetate (PDNPA) ${ }^{12}$ can interact with Nur77 and modulate Nur77. Similarly, Vinayavekhin and Saghatelian ${ }^{13}$

Supported by a US Department of Veterans Affairs merit award and NIH grants HL137842 (R.C.R.) and AI125338 (R.C.R.)

Disclosures: None declared. 
report that the unsaturated fatty acids arachidonic acid and docosahexaenoic acid interact with Nur77 by inducing a conformational change in the Nur77 ligand-binding domain; the authors propose that, in the presence of a ligand, the Nur77 ligand-binding domain assumes a different conformation to generate a cavity that accommodates the small molecule.

Nur77 responds to a wide range of physiological molecules and stimuli. ${ }^{4,14}$ These signals quickly induce Nur77 expression and stimulate its transcriptional activity; Nur77 modulates target gene expression by binding to specific DNA sequences in the genes' promoter regions (Figure 1). ${ }^{3,4,14}$ As a monomer, it binds to the NGFI-B response element. ${ }^{3,14}$ As homodimers or heterodimers with other NR4A family members, it binds to the Nur-response element. ${ }^{3,4,14}$ Nur77 can also heterodimerize with retinoid X receptors (RXRs) to bind to a sequence motif termed DR5 and thereby mediate retinoid signaling. ${ }^{3,4,14}$ In addition, Nur77 can modulate target gene expression independently of DNA binding through its effects on other proteins, such as NF- $\kappa \mathrm{B}$ family members ${ }^{3,14}$ and the zinc finger transcription factor specificity protein $1 .^{15}$

\section{Nur77 Regulation}

\section{Regulation of Nur77 Expression and Activity}

Various transcriptional and post-translational mechanisms that regulate Nur77 expression have been described. In colon cancer cells, the colonic carcinogen deoxycholic acid induces formation of a $\beta$-catenin-c-Fos/c-Jun complex that activates Nur77's promoter, which likely accounts for increased Nur77 expression and the consequent mitogenic effect. ${ }^{16}$ In an in vitro study of maturing thymocytes' negative selection, Nur77 promoter activity and its protein expression were stimulated by apoptotic T-cell receptor signals. ${ }^{17}$ Nur77 NGFI-B response element binding was also detected in this study. During activation-induced thymocyte apoptosis, histone deacetylase 7 can suppress Nur77 expression by interacting with myocyte enhancer factor-2D, a transcription factor that otherwise promotes Nur77 transcription. ${ }^{18,19}$ This and other data indicate that Nur77 expression is controlled in part by histone acetylation. ${ }^{18}$

Nur77 function is also controlled at the posttranscriptional level, predominantly via phosphorylation. Threonine phosphorylation by $\mathrm{p} 38$ was shown to interfere

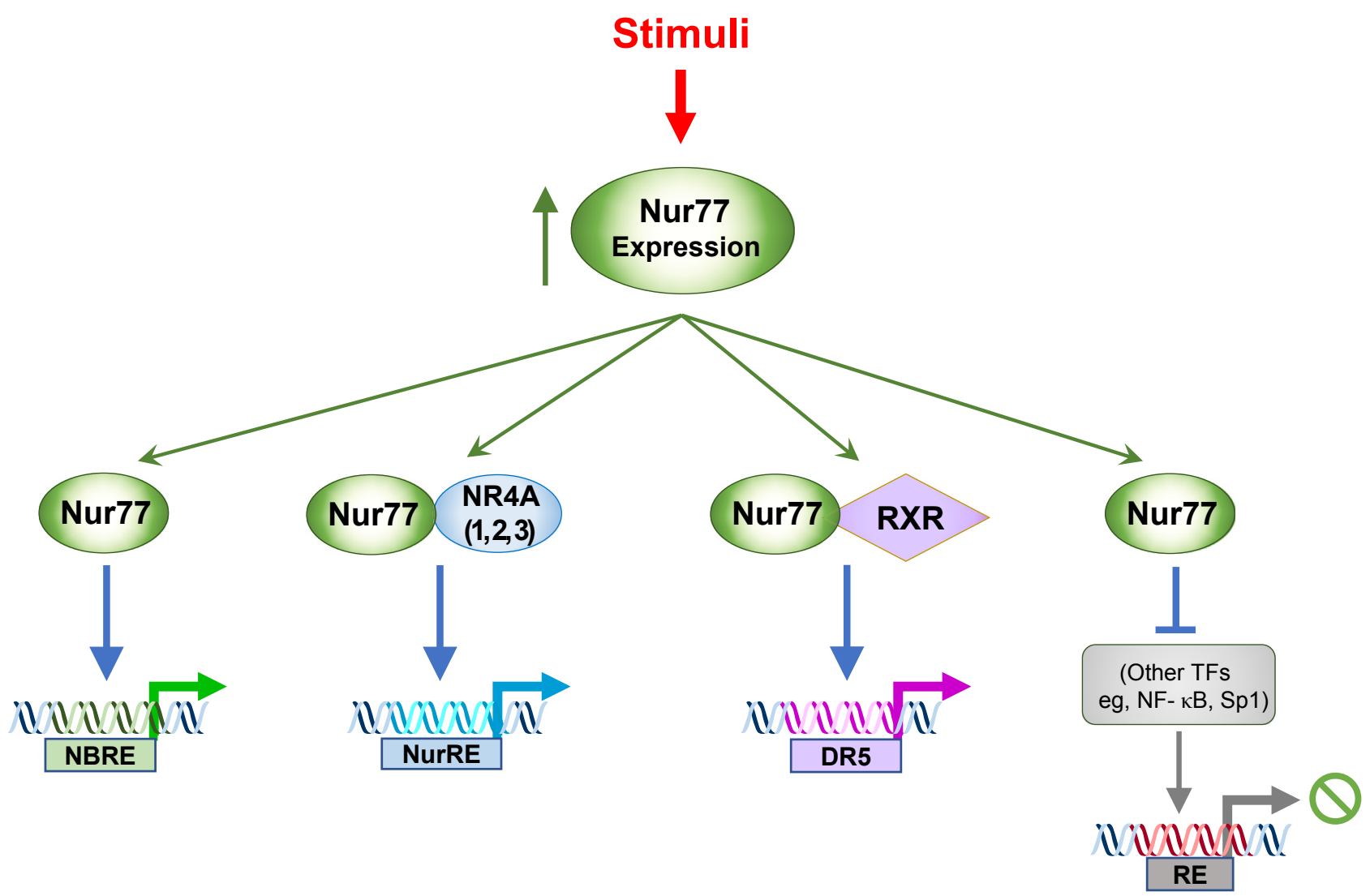

Figure 1 Mechanisms of Nur77's transcriptional activities. On induction by various stimuli, Nur77 modulates target gene expression by binding to specific DNA sequences in their promoters. As a monomer, it binds to the NGFI-B response element (NBRE). As homodimers or heterodimers with Nur-related factor 1 or neuron-derived orphan receptor 1 , it binds to the Nur-response element (NurRE). As heterodimers with retinoid $X$ receptors (RXRs), it binds to a sequence termed DR5. In addition, Nur77 can indirectly suppress gene activity by modulating activities of other proteins, such as members of the NF- $\kappa B$ family and the zinc finger transcription factor (TF) specificity protein $1(\mathrm{Sp} 1)$. RE, response element. 
with Nur77's inhibition of lipopolysaccharide (LPS)induced NF- $\mathrm{NB}$ signaling in a murine macrophage cell line. ${ }^{12}$ Akt also phosphorylated Nur77 and down-regulated its transcriptional activity. ${ }^{20}$ Another study attributed a decrease in Nur77 DNA binding, and consequently its mitogenic effect, to c-Jun N-terminal kinase (JNK)-mediated phosphorylation. ${ }^{21,22}$ This JNK-mediated phosphorylation was also found to trigger Nur77 degradation by the ubiquitin-proteasome pathway. ${ }^{21}$ In contrast, phosphorylation by extracellular signal-regulated kinase 2 protected Nur77 from the ubiquitin-proteasome system and stabilized its expressed protein level by allowing Nur77 to interact with peptidyl-prolyl cis/trans isomerase NIMA-interacting $1 .^{23}$ Moreover, this phosphorylation-dependent interaction with peptidyl-prolyl cis/trans isomerase NIMA-interacting 1 preserved Nur77 transcriptional activity and its mitogenic effect in vitro and in vivo. ${ }^{23}$ These findings demonstrate that Nur77 is under the control of different signals, depending on the cellular/biological context, which may reflect the receptor's versatility as a regulator that can quickly respond to diverse cellular stimuli.

\section{Regulation of Subcellular Localization: Apoptosis versus Survival}

Subcellular localization, specifically nucleus versus mitochondria, is another important area of Nur77 functional regulation. ${ }^{24}$ Nur77 normally resides in the nucleus, ${ }^{16,25,26}$ and this localization is generally associated with a mitogenic effect. ${ }^{16,22}$ On proapoptotic stimulation, however, it translocates to the mitochondria, where it triggers cytochrome $c$ release and cell apoptosis. ${ }^{26,27}$ Although the mechanism underlying Nur77 translocation remains largely unknown, RXR $\alpha$ and B-cell lymphoma-2 (Bcl-2) as well as the mitogen-activated protein kinase and the Akt signaling pathways have emerged as critical players in the two-step process by which Nur77 passes from the nucleus to the cytoplasm and then to the mitochondria. In the absence of RXR agonists, RXR $\alpha$ and Nur77 use their DNA-binding domains to heterodimerize. ${ }^{8,28}$ Through this interaction, RXR $\alpha$ facilitates Nur77's egress from the nucleus to the cytoplasm, using a nuclear export sequence identified within its ligand-binding domain. ${ }^{28}$ Conversely, by interfering with this Nur77-RXR $\alpha$ complex formation and suppressing $\mathrm{RXR} \alpha$ 's nuclear export sequence activity, RXR ligands prevent the cytoplasmic localization of Nur77. ${ }^{28}$ Once localized in the cytoplasm, Nur77 is recruited to the mitochondria by the mitochondrial protein Bcl-2 and mediates apoptosis. ${ }^{29,30}$

Mitogen-activated protein kinase signaling has been shown to promote Nur77's cytoplasmic/mitochondrial localization. JNK-mediated phosphorylation and p38 activation induced Nur77 nuclear export and mitochondrial targeting, respectively. ${ }^{25,31}$ Notably, although Nur77's DNA-binding and transcriptional activities were impaired by JNK phosphorylation, ${ }^{22}$ its ability to promote apoptosis remained unaffected, ${ }^{22,27}$ thus further supporting the correlation between Nur77's cytoplasmic localization and its proapoptotic function. The JNK upstream regulator mitogen-activated protein kinase kinase kinase 1 was also found to assist Nur77 interaction with Bcl-2 by promoting Nur77's translocation from the nucleus to the cytoplasm. ${ }^{25}$ Importantly, nuclear retention or mislocalization elsewhere abolished Nur77's proapoptotic effect. ${ }^{27}$

Opposing the effect of mitogen-activated protein kinase signaling, the well-known prosurvival factor Akt phosphorylated cytoplasmic Nur77 and inhibited its Bcl-2-assisted mitochondrial targeting, consequently suppressing cytochrome $c$ release and apoptosis. ${ }^{30}$ Akt-mediated phosphorylation was also shown to retain Nur77 in the nucleus. ${ }^{25}$ In addition to RXR $\alpha$ ligands and Akt, chromodomain helicase DNA binding protein 1 like was also shown to inhibit apoptosis by binding to Nur77 and blocking Nur77 nuclear export and mitochondria localization. ${ }^{32}$ In sum, all these findings attest to the significant association between subcellular localization and functions of Nur77. Which signal prevails likely depends on the cellular context as well as the kind of stimuli at play. ${ }^{3}$

\section{Nur77 and Inflammation}

Inflammation is a physiologically valuable protective response of tissues to external insults and injury. During this process, a variety of immune mediators are recruited to the damaged tissues to eliminate potentially harmful stimuli and to restore normal structure and function. Without proper, timely resolution, however, this response becomes uncontrolled and chronic, gaining the potential to result in pathologic conditions. At a general level, uncontrolled inflammation can be viewed as an imbalance between proinflammatory and anti-inflammatory factors. Inflammatory stimuli, such as tumor necrosis factor- $\alpha$, Toll-like receptor ligands, and oxidized lipids, have been shown to induce nuclear Nur77 expression, supporting its role in inflammatory responses. ${ }^{33}$ Furthermore, studies have suggested Nur77's potential to alleviate various inflammatory diseases $^{34-40}$ and propose that, like other members of the nuclear hormone receptor superfamily (eg, the peroxisome proliferator-activated receptors, the glucocorticoid receptors, and the retinoid receptors), Nur77 may be an attractive target for inflammatory disease therapies.

\section{Suppression of Inflammation and Regulation of the NF- $\kappa B$ Pathway and Macrophage Functions}

NF- $\kappa \mathrm{B}$ signaling is a major driver of inflammatory responses. ${ }^{41}$ When activated, NF- $\kappa \mathrm{B}$ stimulates inflammatory responses in multiple cell types and promotes expression and activity of proinflammatory mediators, such as cytokines, chemokines, and adhesion molecules. Nur77 responds to NF$\kappa \mathrm{B}$ signaling and, in turn, down-regulates this master regulator of inflammation in a negative feedback manner. ${ }^{14}$ A genomic 


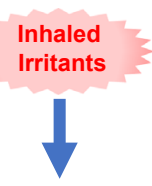

Proinflammatory Signals

(eg, TNF- $\alpha$, IL-1 $1 \beta$, OxLipids, TLRs)

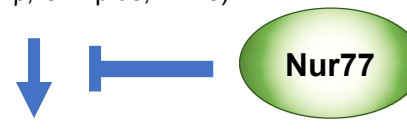

\section{Endothelial Cells}

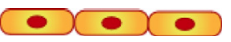

Adhesion Molecules
(eg, ICAM-1, VCAM-1)

Damaged Epithelial layer

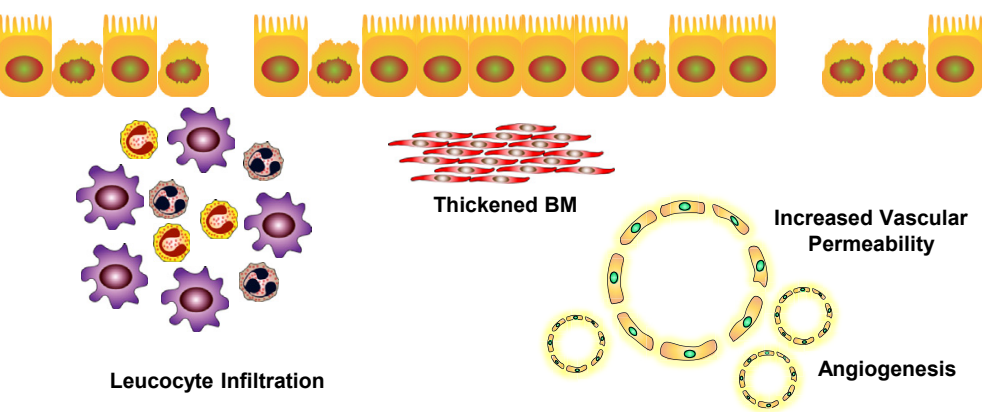

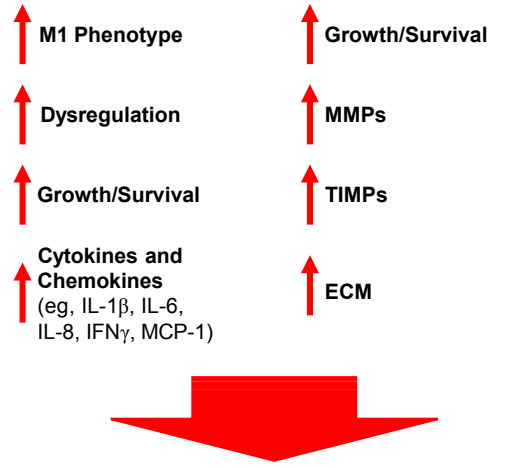

Inflammation and Lung Diseases

\section{Other Cell Types}
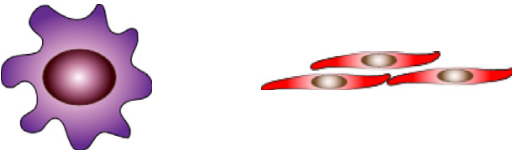

eg, Neutrophils, Eosinophils and Fibroblasts

Dysregulation

Growth/Survival
Macrophages

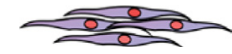

Figure 2 Nur77-mediated regulation of inflammation and lung diseases. Inhaled irritants up-regulate proinflammatory signals, such as tumor necrosis factor (TNF)- $\alpha$, IL-1 $\beta$, oxidized lipids (OxLipids), and Toll-like receptors (TLRs), in airway cells, which, in turn, induce Nur77 expression. Once expressed, Nur77 suppresses production of various molecules [eg, adhesion molecules, cytokines, chemokines, matrix metalloproteinases (MMPs) and their inhibitors (TIMPs), and extracellular matrix (ECM)] and cellular processes (eg, enhanced proinflammatory activities and phenotype, growth, and survival). Consequently, the extent of inflammatory responses and inflammation-induced tissue damage and remodeling, such as basement membrane (BM) and vasculature remodeling, are expected to remain under control. ICAM-1, intercellular adhesion molecule-1; IFN- $\gamma$, interferon- $\gamma$; MCP-1, monocyte chemoattractant protein-1; VCAM-1, vascular cell adhesion molecule-1. analysis using in vitro modeling of monocyte adherence also identified Nur77 as a potent NF- $\kappa B$ inhibitor. ${ }^{42}$ Notably, its ability to suppress tumor necrosis factor- $\alpha-$ and IL$1 \beta$-induced NF- $\kappa \mathrm{B}$ activation was comparable to that of the well-characterized NF- $\kappa \mathrm{B}$ inhibitor $\mathrm{I} \kappa \mathrm{B} \alpha$, substantiating its role as a regulator of the NF- $\kappa \mathrm{B}$ pathway and thereby of inflammation.

Several studies, most focusing on macrophages, have reported that Nur77 counteracts inflammatory responses in multiple ways. For example, Nur77 deficiency elevated production of inflammatory mediators, such as IL-1 $\beta$, IL-6, tumor necrosis factor- $\alpha$, and nitric oxide, in two mouse models of sepsis. ${ }^{12}$ Specifically, Nur77 was found to produce its anti-inflammatory effects by inhibiting NF- $\kappa \mathrm{B} / \mathrm{p} 65$ transcriptional activity. ${ }^{12}$ Monocyte/macrophage adhesion to endothelial cells, an important step in atherogenesis, is facilitated by adhesion molecules, including vascular cell adhesion molecule- 1 and intercellular adhesion molecule- $1 .{ }^{43}$ Tumor necrosis factor- $\alpha-$ and IL- $1 \beta$-induced expression of these proteins by a human endothelial cell line was attenuated by Nur77 overexpression, an effect mediated via NF- $\mathrm{KB}$ repression, whereas Nur77 knockdown exhibited an opposite effect. ${ }^{43}$ Consequently, monocyte adhesion to endothelial cells was reduced by exogenous Nur77. ${ }^{43}$ Nur77 also regulated expression of matrix metalloproteinases, their inhibitors, and extracellular matrix protein collagen, ${ }^{14,44}$ which 
is expected to affect leukocyte infiltration during inflammation. Nur77's role in the regulation of adhesion molecules and matrix metalloproteinases was also reflected by the enhanced migration of macrophages in Nur77-deficient mice. ${ }^{34}$ In addition, Nur77 deficiency steered macrophage differentiation toward a proinflammatory M1 phenotype. ${ }^{34,35,45}$ Lastly, Nur77 has been shown to partake in the activation-induced death of macrophages, a phenomenon presumably intended to control the extent of immune responses. ${ }^{46}$ Together, these data support Nur77's role as a negative regulator of the macrophage functions that drive exaggerated inflammatory responses (Figure 2).

\section{Nur77 in Inflammation-Related Lung Diseases}

Studies focusing on Nur77's role in lung pathophysiology are currently limited. Yet, Nur77's pulmonary expression, together with its anti-inflammatory properties and its protective effect against tissue damage that was reported in a study using a rat model of acute respiratory distress syndrome ${ }^{47}$ suggests that it may have important functions in the lungs. Furthermore, microarray data complemented by gene set enrichment analyses and Ingenuity pathway analyses identified Nur77's association with chronic obstructive pulmonary disease and allergic airway inflammatory disease, respectively. ${ }^{44}$

\section{Asthma}

Asthma is a respiratory disease that features airway inflammation and tissue remodeling. Many, but not all, asthma cases are due to allergic reactions, but the specific allergens involved are often unidentified. ${ }^{48}$ Currently, many patients experience a progressive decline of lung function despite treatment. ${ }^{49}$ Ozone and house dust mite antigen are two common lung irritants that have been used in preclinical models of asthma. ${ }^{50}$ These inhaled agents, which produce the goblet cell hyperplasia and thickened basement membrane associated with the disease, induced Nur77 expression in the airway epithelium of monkeys. ${ }^{50}$ The airway epithelium of animals subjected to ozone inhalation also displayed positive staining for the cell death marker ethidium homodimer-1 that overlapped with staining for Nur77, which implies that Nur77-triggered apoptosis contributed to the epithelial cell loss/injury associated with ozone exposure. ${ }^{51}$ In contrast to the undesirable effect of Nur77 expression suggested by Murphy et al, ${ }^{50,51}$ a study using a mouse model of allergic airway disease reported that Nur77 controlled ovalbumininduced airway inflammation by counteracting NF- $\kappa \mathrm{B}$ signaling in lung epithelial cells. ${ }^{36}$ This study further showed that Nur77-deficient animals displayed exacerbated inflammatory responses characterized by increased leukocyte infiltration, mucus hypersecretion, and enhanced production of chemokines and cytokines. ${ }^{36}$ Because smooth muscle hypertrophy/hyperplasia is another prominent feature of asthma ${ }^{52}$ benefits of Nur77 expression in asthma can also be expected from its ability to suppress smooth muscle cell proliferation, as demonstrated by a study of pulmonary arterial hypertension associated with vascular remodeling. ${ }^{53}$ Future investigation will be necessary to clarify the apparent discrepancy between the studies mentioned. One plausible explanation is that, reflecting its functional flexibility as an immediate early gene responding to diverse triggers, Nur77's influence on asthma pathogenesis varies with the inducing agent.

\section{Acute Lung Injury}

Acute lung injury and acute respiratory distress syndrome are disorders of exaggerated inflammatory responses to various insults that damage the lung endothelium and epithelium. With gas exchange impaired, patients experiencing acute lung injury often experience respiratory failure; these conditions are thus associated with high morbidity and mortality. ${ }^{54,55}$

Acute respiratory distress syndrome patients, ${ }^{56,57}$ as well as rats with sepsis-induced acute lung injury, ${ }^{58}$ have been observed to have elevated expression of endothelin-1, a peptide with proinflammatory properties. In an in vitro study, Nur77 knockdown enhanced and overexpression suppressed both basal and LPS-induced expression of endothelin-1. ${ }^{47}$ Likewise, an increase in endothelin-1 expression in the lungs of LPS-exposed rats was blocked by pretreatment with the Nur77 activator cytosporone B. ${ }^{47}$ This suppression of endothelin-1 expression was shown to be mediated through Nur77's down-regulation of activationmediated NF- $\kappa \mathrm{B}$ signaling. Additional studies are necessary to further define Nur77's role in the pathophysiology of acute lung injury/acute respiratory distress syndrome. However, currently available data suggest that pharmacologic activation of Nur77 may provide a therapeutic benefit in these conditions.

\section{Pulmonary Fibrosis}

During tissue repair after injury, transforming growth factor$\beta$ (TGF- $\beta$ ) signaling stimulates fibroblasts to deposit extracellular matrix components into and around the damaged area. ${ }^{59}$ This TGF- $\beta$-driven physiological process normally discontinues on completion of the repair. However, in pathologic conditions, persistent TGF- $\beta$ signaling disrupts tissue homeostasis, leading to fibrosis characterized by accumulation of extracellular matrix as well as altered tissue structure and function. Inflammatory diseases of several organs, including the lungs, are associated with fibrosis.

Enhanced Nur77 expression was found in the lungs of patients with idiopathic pulmonary fibrosis as well as in the fibrotic skin of those with systemic sclerosis and the livers of alcoholic liver cirrhosis patients. ${ }^{59}$ In experimental fibrosis induced by constitutively active TGF- $\beta$ receptor type I, Nur77 
Table 1 Summary of Potentially Therapeutic Molecules That Modulate Nur77

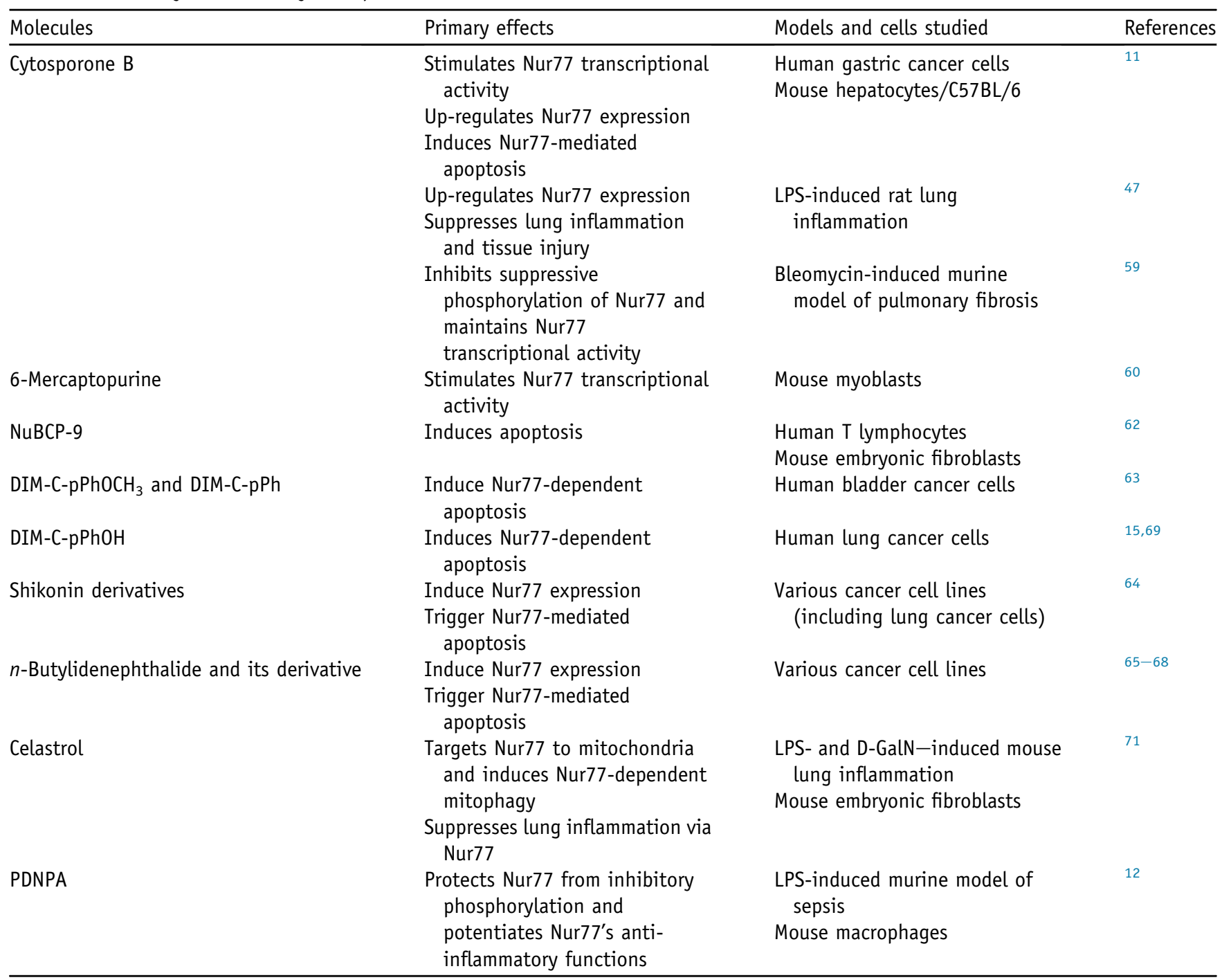

LPS, lipopolysaccharide; PDNPA, n-pentyl 2-[3,5-dihydroxy-2-(1-nonanoyl)-phenyl]acetate.

deficiency further enhanced TGF- $\beta$ signaling (as indicated by increased expression of its target genes) and aggravated the disease, as shown by extensive collagen deposition and an increased number of myofibroblasts. ${ }^{59}$ Likewise, Nur77deficient mice were more susceptible to bleomycin-induced pulmonary fibrosis. Together, these data indicate that Nur77 regulates fibrosis and imply that it is somehow dys/unfunctional in fibrotic conditions. Supporting this concept, PalumboZerr et $\mathrm{al}^{59}$ demonstrated that, despite elevated total protein expression, the accumulated Nur77 in the fibrotic tissues was phosphorylated. Because phosphorylation has been associated with suppression of Nur77 activity, Nur77 in the affected tissues is expected to be functionally impaired, ${ }^{59}$ thus explaining the exacerbated fibrotic features. This study proposes Nur77 as a negative regulator of the TGF- $\beta$ pathway during wound healing. It further suggests that pathologic conditions impair this Nur77-mediated negative feedback loop, leading to persistent TGF- $\beta$ signaling and thus enhanced fibrogenesis. In sum, Nur77 may represent a novel therapeutic target for pulmonary fibrosis.

\section{Nur77 as Therapeutic Target for Lung Inflammation and Diseases}

Although endogenous ligands have not yet been identified, and may not exist, accumulating evidence suggests that diverse molecules can interact directly with the Nur77 receptor and modulate its activity.

\section{Transcription Activators}

Cytosporone $\mathrm{B}$ is a fungal metabolite that physically binds to Nur77; it stimulates transcription of an Nur-response element reporter gene and up-regulates Nur77 expression via enhancement of its promoter activity in an autoregulatory 
manner. ${ }^{11}$ In rats with LPS-induced lung inflammation, cytosporone B treatment suppressed induction of endothelin-1 expression by increasing Nur77 mRNA and protein expression. ${ }^{47}$ It also lessened capillary barrier dysfunction (as indicated by decreases in bronchoalveolar lavage protein concentration and lung wet/dry weight ratio) and tissue injury in the lungs of LPS-exposed animals. Cytosporone B likewise alleviated bleomycin-induced pulmonary fibrosis by protecting Nur77 from suppressive phosphorylation. ${ }^{59}$ Importantly, established fibrosis also resolved effectively after cytosporone $\mathrm{B}$ treatment, a finding of clinical relevance. Interestingly, the anti-inflammatory purine antimetabolite 6-mercaptopurine was also shown to stimulate Nur77's transcriptional activity and enhance expression of Nur-response element reporter gene. ${ }^{60}$ Although cytosporone $\mathrm{B}$ appears promising, further investigation is required to assess the therapeutic application of this and other Nur77-activating molecules for inflammationrelated lung diseases.

\section{Apoptosis Inducers}

For inflammation and other diseases associated with uncontrolled expression and/or activity of certain cells (eg, macrophages ${ }^{46}$ fibroblasts, ${ }^{48,61}$ and smooth muscle cells ${ }^{52}$ ), restraining or reversing such dysregulation is therapeutically critical. A 9-amino acid Nur77 fragment, NuBCP-9, which was found to induce apoptosis via the $\mathrm{Bcl}-2$ signaling pathway in human $\mathrm{T}$ lymphocytes as well as in mouse embryonic fibroblasts, ${ }^{62}$ could thus be a valuable tool in such diseases. Analogs of methylene-substituted diindolylmethane derived from cruciferous vegetables (DIM-C-pPhOCH${ }_{3}$ and DIM-C$\mathrm{pPh}){ }^{63}$ shikonin derivatives extracted from the medicinal plant Lithospermum erythrorhizon, ${ }^{64}$ and $n$-butylidenephthalide and its derivative extracted from another plant, Angelica sinensis, ${ }^{65-68}$ have also been shown to induce Nur77-dependent apoptosis of various cell types. Another methylene-substituted diindolylmethane analog, DIM-C-pPhOH, triggers apoptosis in lung cancer cells. ${ }^{15,69}$ Interestingly, however, in contrast to the molecular mechanisms of DIM-C-pPhOCH 3 and DIM-C$\mathrm{pPh}$, this proapoptotic effect of DIM-C-pPhOH was dependent on the compound deactivating Nur $77 .{ }^{15}$ These findings suggest that biological effects of ligand binding to Nur77 may be cell type or disease specific and support further investigation of these compounds' effects as apoptosis inducers on lung inflammation and diseases.

\section{Anti-Inflammatory Agents}

Metabolically active pulmonary cells as well as immune cells use mitophagy to counteract mitochondrial stress and damage. ${ }^{70}$ Accordingly, irreparable mitochondrial damage or dysfunction as well as failed or inadequate mitophagy can lead to lung inflammation or disease. ${ }^{70}$ Celastrol, a pentacyclic triterpenoid quinine methide extracted from Tripterygium wilfordii, was found to control lung inflammation by targeting Nur77 to mitochondria and inducing Nur77-dependent mitophagy. ${ }^{71}$ Celastrol's anti-inflammatory effects have also been reported in other inflammatory diseases. ${ }^{72}$ Although its clinical application has yet to overcome limitations, such as toxicity and insolubility, ${ }^{72}$ this natural compound provides a useful in vitro tool to study Nur77's role in mitophagy and inflammation.

PDNPA is a synthetic compound found to interact with Nur77. ${ }^{12}$ This interaction interfered with LPS-induced interaction between Nur77 and p38 and the consequent inhibitory phosphorylation of Nur77, thus allowing the receptor to suppress NF- $\kappa \mathrm{B}$ signaling and the resulting proinflammatory cytokine secretion. PDNPA treatment accordingly attenuated LPS-induced experimental sepsis. ${ }^{12}$ Although PDNPA's efficacy to resolve lung inflammation has not been examined to date, its negative effect on NF- $\kappa B$, a central figure of inflammatory responses, makes this drug a worthy target of future research.

\section{Conclusions}

Nur77 is emerging as a noteworthy regulator of inflammation in diverse biological contexts. Pharmacologic agents that can modulate its expression and activity have also shown promising effects in several experimental systems relevant to inflammation (Table 1). Nevertheless, data on Nur77 functions in lung physiology and its role in lung inflammation and diseases are currently scarce. Thus, although available data are encouraging, definitive identification of Nur77 as a therapeutic target will require more detailed characterization. To this end, future research should delineate how the effects of Nur77 activity vary with subcellular localization, cell type, and cellular context, as well as with the kinds of stimuli modulating its expression and activity. A better understanding of how genomic and nongenomic functions are switched on and off will also likely aid the development of Nur77's pharmacologic modulators and their clinical application.

Finally, investigations assessing Nur77's prospect as a therapeutic target should also address the implications of functional redundancy between NR4A receptor subfamily members. Consistent with the significant homology in their DNA binding domains, ${ }^{4,8}$ the dominant-negative Nur77 mutant was capable of inhibiting transactivation activity not only of Nur77 but also of Nurr1 and neuron-derived orphan receptor $1 .^{73}$ Conversely, the apparently normal phenotype of Nur77-deficient mice ${ }^{74}$ hints at functional compensation by Nurr1 and neuron-derived orphan receptor 1 for the loss of Nur77. ${ }^{46,73,75}$ Thus, strategies that use pharmacologic targeting of Nur77 will need to consider their possible influence on other NR4A members and the functional consequences thereof.

\section{Supplemental Data}

Supplemental material for this article can be found at https://doi.org/10.1016/j.ajpath.2018.10.002. 


\section{References}

1. Hazel TG, Nathans D, Lau LF: A gene inducible by serum growth factors encodes a member of the steroid and thyroid hormone receptor superfamily. Proc Natl Acad Sci U S A 1988, 85:8444-8448

2. Davis IJ, Hazel TG, Lau LF: Transcriptional activation by Nur77, a growth factor-inducible member of the steroid hormone receptor superfamily. Mol Endocrinol 1991, 5:854-859

3. To SK, Zeng JZ, Wong AS: Nur77: a potential therapeutic target in cancer. Expert Opin Ther Targets 2012, 16:573-585

4. Maxwell MA, Muscat GE: The NR4A subgroup: immediate early response genes with pleiotropic physiological roles. Nucl Recept Signal 2006, 4:e002

5. Law SW, Conneely OM, DeMayo FJ, O’Malley BW: Identification of a new brain-specific transcription factor, NURR1. Mol Endocrinol 1992, 6:2129-2135

6. Ohkura N, Hijikuro M, Yamamoto A, Miki K: Molecular cloning of a novel thyroid/steroid receptor superfamily gene from cultured rat neuronal cells. Biochem Biophys Res Commun 1994, 205: $1959-1965$

7. Kumar R, Thompson EB: The structure of the nuclear hormone receptors. Steroids 1999, 64:310-319

8. Kurakula K, Koenis DS, van Tiel CM, de Vries CJ: NR4A nuclear receptors are orphans but not lonesome. Biochim Biophys Acta 2014, $1843: 2543-2555$

9. Wang Z, Benoit G, Liu J, Prasad S, Aarnisalo P, Liu X, Xu H, Walker NP, Perlmann T: Structure and function of Nurr1 identifies a class of ligandindependent nuclear receptors. Nature 2003, 423:555-560

10. Flaig R, Greschik H, Peluso-Iltis C, Moras D: Structural basis for the cell-specific activities of the NGFI-B and the Nurr1 ligand-binding domain. J Biol Chem 2005, 280:19250-19258

11. Zhan Y, Du X, Chen H, Liu J, Zhao B, Huang D, Li G, Xu Q, Zhang M, Weimer BC, Chen D, Cheng Z, Zhang L, Li Q, Li S, Zheng Z, Song S, Huang Y, Ye Z, Su W, Lin SC, Shen Y, Wu Q: Cytosporone B is an agonist for nuclear orphan receptor Nur77. Nat Chem Biol 2008, 4:548-556

12. Li L, Liu Y, Chen HZ, Li FW, Wu JF, Zhang HK, He JP, Xing YZ, Chen Y, Wang WJ, Tian XY, Li AZ, Zhang Q, Huang PQ, Han J, Lin T, Wu Q: Impeding the interaction between Nur77 and p38 reduces LPS-induced inflammation. Nat Chem Biol 2015, 11:339-346

13. Vinayavekhin N, Saghatelian A: Discovery of a protein-metabolite interaction between unsaturated fatty acids and the nuclear receptor Nur77 using a metabolomics approach. J Am Chem Soc 2011, 133: $17168-17171$

14. Rodriguez-Calvo R, Tajes M, Vazquez-Carrera M: The NR4A subfamily of nuclear receptors: potential new therapeutic targets for the treatment of inflammatory diseases. Expert Opin Ther Targets 2017, 21:291-304

15. Lee SO, Andey T, Jin UH, Kim K, Singh M, Safe S: The nuclear receptor TR3 regulates mTORC1 signaling in lung cancer cells expressing wild-type p53. Oncogene 2012, 31:3265-3276

16. Wu H, Lin Y, Li W, Sun Z, Gao W, Zhang H, Xie L, Jiang F, Qin B, Yan T, Chen L, Zhao Y, Cao X, Wu Y, Lin B, Zhou H, Wong AS, Zhang XK, Zeng JZ: Regulation of Nur77 expression by beta-catenin and its mitogenic effect in colon cancer cells. FASEB J 2011, 25: 192-205

17. Woronicz JD, Lina A, Calnan BJ, Szychowski S, Cheng L, Winoto A: Regulation of the Nur77 orphan steroid receptor in activation-induced apoptosis. Mol Cell Biol 1995, 15:6364-6376

18. Dequiedt F, Kasler H, Fischle W, Kiermer V, Weinstein M, Herndier BG, Verdin E: HDAC7, a thymus-specific class II histone deacetylase, regulates Nur77 transcription and TCR-mediated apoptosis. Immunity 2003, 18:687-698

19. McKinsey TA, Zhang CL, Olson EN: MEF2: a calcium-dependent regulator of cell division, differentiation and death. Trends Biochem Sci 2002, 27:40-47
20. Pekarsky Y, Hallas C, Palamarchuk A, Koval A, Bullrich F, Hirata Y, Bichi R, Letofsky J, Croce CM: Akt phosphorylates and regulates the orphan nuclear receptor Nur77. Proc Natl Acad Sci U S A 2001, 98 : 3690-3694

21. Liu B, Wu JF, Zhan YY, Chen HZ, Zhang XY, Wu Q: Regulation of the orphan receptor TR3 nuclear functions by c-Jun $\mathrm{N}$ terminal kinase phosphorylation. Endocrinology 2007, 148:34-44

22. Kolluri SK, Bruey-Sedano N, Cao X, Lin B, Lin F, Han YH, Dawson MI, Zhang XK: Mitogenic effect of orphan receptor TR3 and its regulation by MEKK1 in lung cancer cells. Mol Cell Biol 2003, 23:8651-8667

23. Chen HZ, Li L, Wang WJ, Du XD, Wen Q, He JP, Zhao BX, Li GD, Zhou W, Xia Y, Yang QY, Hew CL, Liou YC, Wu Q: Prolyl isomerase Pin1 stabilizes and activates orphan nuclear receptor TR3 to promote mitogenesis. Oncogene 2012, 31:2876-2887

24. Zhang XK: Targeting Nur77 translocation. Expert Opin Ther Targets 2007, 11:69-79

25. Han YH, Cao X, Lin B, Lin F, Kolluri SK, Stebbins J, Reed JC, Dawson MI, Zhang XK: Regulation of Nur77 nuclear export by c-Jun N-terminal kinase and Akt. Oncogene 2006, 25:2974-2986

26. Cheng Z, Volkers M, Din S, Avitabile D, Khan M, Gude N, Mohsin S, Bo T, Truffa S, Alvarez R, Mason M, Fischer KM, Konstandin MH, Zhang XK, Heller Brown J, Sussman MA: Mitochondrial translocation of Nur77 mediates cardiomyocyte apoptosis. Eur Heart J 2011, 32:2179-2188

27. Li H, Kolluri SK, Gu J, Dawson MI, Cao X, Hobbs PD, Lin B, Chen G, Lu J, Lin F, Xie Z, Fontana JA, Reed JC, Zhang X: Cytochrome $\mathrm{c}$ release and apoptosis induced by mitochondrial targeting of nuclear orphan receptor TR3. Science 2000, 289:1159-1164

28. Cao X, Liu W, Lin F, Li H, Kolluri SK, Lin B, Han YH, Dawson MI, Zhang XK: Retinoid X receptor regulates Nur77/TR3-dependent apoptosis [corrected] by modulating its nuclear export and mitochondrial targeting. Mol Cell Biol 2004, 24:9705-9725

29. Lin B, Kolluri SK, Lin F, Liu W, Han YH, Cao X, Dawson MI, Reed JC, Zhang XK: Conversion of Bcl-2 from protector to killer by interaction with nuclear orphan receptor Nur77/TR3. Cell 2004, 116: $527-540$

30. Chen HZ, Zhao BX, Zhao WX, Li L, Zhang B, Wu Q: Akt phosphorylates the TR3 orphan receptor and blocks its targeting to the mitochondria. Carcinogenesis 2008, 29:2078-2088

31. Holmes WF, Soprano DR, Soprano KJ: Early events in the induction of apoptosis in ovarian carcinoma cells by CD437: activation of the p38 MAP kinase signal pathway. Oncogene 2003, 22:6377-6386

32. Chen L, Hu L, Chan TH, Tsao GS, Xie D, Huo KK, Fu L, Ma S, Zheng BJ, Guan XY: Chromodomain helicase/adenosine triphosphatase DNA binding protein 1-like (CHD11) gene suppresses the nucleus-to-mitochondria translocation of nur77 to sustain hepatocellular carcinoma cell survival. Hepatology 2009, 50:122-129

33. Pei L, Castrillo A, Chen M, Hoffmann A, Tontonoz P: Induction of NR4A orphan nuclear receptor expression in macrophages in response to inflammatory stimuli. J Biol Chem 2005, 280: 29256-29262

34. Hamers AA, Vos M, Rassam F, Marinkovic G, Kurakula K, van Gorp PJ, de Winther MP, Gijbels MJ, de Waard V, de Vries CJ: Bone marrow-specific deficiency of nuclear receptor Nur77 enhances atherosclerosis. Circ Res 2012, 110:428-438

35. Hanna RN, Shaked I, Hubbeling HG, Punt JA, Wu R, Herrley E, Zaugg C, Pei H, Geissmann F, Ley K, Hedrick CC: NR4A1 (Nur77) deletion polarizes macrophages toward an inflammatory phenotype and increases atherosclerosis. Circ Res 2012, 110:416-427

36. Kurakula K, Vos M, Logiantara A, Roelofs JJ, Nieuwenhuis MA, Koppelman GH, Postma DS, van Rijt LS, de Vries CJ: Nuclear receptor Nur77 attenuates airway inflammation in mice by suppressing NF-kappaB activity in lung epithelial cells. J Immunol 2015, 195: $1388-1398$

37. Chao LC, Wroblewski K, Zhang Z, Pei L, Vergnes L, Ilkayeva OR, Ding SY, Reue K, Watt MJ, Newgard CB, Pilch PF, Hevener AL, 
Tontonoz P: Insulin resistance and altered systemic glucose metabolism in mice lacking Nur77. Diabetes 2009, 58:2788-2796

38. De Silva S, Han S, Zhang X, Huston DP, Winoto A, Zheng B: Reduction of the incidence and severity of collagen-induced arthritis by constitutive Nur77 expression in the $\mathrm{T}$ cell lineage. Arthritis Rheum 2005, 52:333-338

39. Hamers AA, van Dam L, Teixeira Duarte JM, Vos M, Marinkovic G, van Tiel CM, Meijer SL, van Stalborch AM, Huveneers S, Te Velde AA, de Jonge WJ, de Vries CJ: Deficiency of nuclear receptor Nur77 aggravates mouse experimental colitis by increased NFkappaB activity in macrophages. PLoS One 2015, 10:e0133598

40. Wu H, Li XM, Wang JR, Gan WJ, Jiang FQ, Liu Y, Zhang XD, He XS, Zhao YY, Lu XX, Guo YB, Zhang XK, Li JM: NUR77 exerts a protective effect against inflammatory bowel disease by negatively regulating the TRAF6/TLR-IL-1R signalling axis. J Pathol 2016, 238: $457-469$

41. Lawrence T: The nuclear factor NF-kappaB pathway in inflammation. Cold Spring Harb Perspect Biol 2009, 1:a001651

42. Diatchenko L, Romanov S, Malinina I, Clarke J, Tchivilev I, Li X, Makarov SS: Identification of novel mediators of NF-kappaB through genome-wide survey of monocyte adherence-induced genes. J Leukoc Biol 2005, 78:1366-1377

43. You B, Jiang YY, Chen S, Yan G, Sun J: The orphan nuclear receptor Nur77 suppresses endothelial cell activation through induction of IkappaBalpha expression. Circ Res 2009, 104:742-749

44. Hamers AA, Argmann C, Moerland PD, Koenis DS, Marinkovic G, Sokolovic M, de Vos AF, de Vries CJ, van Tiel CM: Nur77deficiency in bone marrow-derived macrophages modulates inflammatory responses, extracellular matrix homeostasis, phagocytosis and tolerance. BMC Genomics 2016, 17:162

45. Li XM, Lu XX, Xu Q, Wang JR, Zhang S, Guo PD, Li JM, Wu H: Nur77 deficiency leads to systemic inflammation in elderly mice. J Inflamm (Lond) 2015, 12:40

46. Kim SO, Ono K, Tobias PS, Han J: Orphan nuclear receptor Nur77 is involved in caspase-independent macrophage cell death. J Exp Med 2003, 197:1441-1452

47. Jiang Y, Zeng Y, Huang X, Qin Y, Luo W, Xiang S, Sooranna SR, Pinhu L: Nur77 attenuates endothelin-1 expression via downregulation of NF-kappaB and p38 MAPK in A549 cells and in an ARDS rat model. Am J Physiol Lung Cell Mol Physiol 2016, 311: L1023-L1035

48. Shifren A, Witt C, Christie C, Castro M: Mechanisms of remodeling in asthmatic airways. J Allergy (Cairo) 2012, 2012:316049

49. Pascual RM, Peters SP: Airway remodeling contributes to the progressive loss of lung function in asthma: an overview. J Allergy Clin Immunol 2005, 116:477-486

50. Murphy SR, Schelegle ES, Edwards PC, Miller LA, Hyde DM, Van Winkle LS: Postnatal exposure history and airways: oxidant stress responses in airway explants. Am J Respir Cell Mol Biol 2012, 47: $815-823$

51. Murphy SR, Oslund KL, Hyde DM, Miller LA, Van Winkle LS, Schelegle ES: Ozone-induced airway epithelial cell death, the neurokinin-1 receptor pathway, and the postnatal developing lung. Am J Physiol Lung Cell Mol Physiol 2014, 307: L471-L481

52. Benayoun L, Druilhe A, Dombret MC, Aubier M, Pretolani M: Airway structural alterations selectively associated with severe asthma. Am J Respir Crit Care Med 2003, 167:1360-1368

53. Liu Y, Zhang J, Yi B, Chen M, Qi J, Yin Y, Lu X, Jasmin JF, Sun J: Nur77 suppresses pulmonary artery smooth muscle cell proliferation through inhibition of the STAT3/Pim-1/NFAT pathway. Am J Respir Cell Mol Biol 2014, 50:379-388

54. Ragaller M, Richter T: Acute lung injury and acute respiratory distress syndrome. J Emerg Trauma Shock 2010, 3:43-51

55. Johnson ER, Matthay MA: Acute lung injury: epidemiology, pathogenesis, and treatment. J Aerosol Med Pulm Drug Deliv 2010, 23: $243-252$
56. Albertine KH, Wang ZM, Michael JR: Expression of endothelial nitric oxide synthase, inducible nitric oxide synthase, and endothelin-1 in lungs of subjects who died with ARDS. Chest 1999, 116:101S-102S

57. Nakano Y, Tasaka S, Saito F, Yamada W, Shiraishi Y, Ogawa Y, Koh H, Hasegawa N, Fujishima S, Hashimoto S, Ishizaka A: Endothelin-1 level in epithelial lining fluid of patients with acute respiratory distress syndrome. Respirology 2007, 12:740-743

58. Jesmin S, Yamaguchi N, Zaedi S, Nusrat Sultana S, Iwashima Y, Sawamura A, Gando S: Time-dependent expression of endothelin-1 in lungs and the effects of TNF-alpha blocking peptide on acute lung injury in an endotoxemic rat model. Biomed Res 2011, 32:9-17

59. Palumbo-Zerr K, Zerr P, Distler A, Fliehr J, Mancuso R, Huang J, Mielenz D, Tomcik M, Furnrohr BG, Scholtysek C, Dees C, Beyer C, Kronke G, Metzger D, Distler O, Schett G, Distler JH: Orphan nuclear receptor NR4A1 regulates transforming growth factor-beta signaling and fibrosis. Nat Med 2015, 21:150-158

60. Wansa KD, Harris JM, Yan G, Ordentlich P, Muscat GE: The AF-1 domain of the orphan nuclear receptor NOR-1 mediates transactivation, coactivator recruitment, and activation by the purine antimetabolite 6-mercaptopurine. J Biol Chem 2003, 278:24776-24790

61. Boulet LP, Laviolette M, Turcotte H, Cartier A, Dugas M, Malo JL, Boutet M: Bronchial subepithelial fibrosis correlates with airway responsiveness to methacholine. Chest 1997, 112:45-52

62. Kolluri SK, Zhu X, Zhou X, Lin B, Chen Y, Sun K, Tian X, Town J, Cao X, Lin F, Zhai D, Kitada S, Luciano F, O'Donnell E, Cao Y, He F, Lin J, Reed JC, Satterthwait AC, Zhang XK: A short Nur77derived peptide converts $\mathrm{Bcl}-2$ from a protector to a killer. Cancer Cell 2008, 14:285-298

63. Cho SD, Lee SO, Chintharlapalli S, Abdelrahim M, Khan S, Yoon K, Kamat AM, Safe S: Activation of nerve growth factor-induced B alpha by methylene-substituted diindolylmethanes in bladder cancer cells induces apoptosis and inhibits tumor growth. Mol Pharmacol 2010, 77:396-404

64. Liu J, Zhou W, Li SS, Sun Z, Lin B, Lang YY, He JY, Cao X, Yan T, Wang L, Lu J, Han YH, Cao Y, Zhang XK, Zeng JZ: Modulation of orphan nuclear receptor Nur77-mediated apoptotic pathway by acetylshikonin and analogues. Cancer Res 2008, 68:8871-8880

65. Liu PY, Sheu JJ, Lin PC, Lin CT, Liu YJ, Ho LI, Chang LF, Wu WC, Chen SR, Chen J, Harn YC, Lin SZ, Tsai CH, Chiou TW, Harn HJ: Expression of Nur77 induced by an n-butylidenephthalide derivative promotes apoptosis and inhibits cell growth in oral squamous cell carcinoma. Invest New Drugs 2012, 30:79-89

66. Lin PC, Chen YL, Chiu SC, Yu YL, Chen SP, Chien MH, Chen KY, Chang WL, Lin SZ, Chiou TW, Harn HJ: Orphan nuclear receptor, Nurr-77 was a possible target gene of butylidenephthalide chemotherapy on glioblastoma multiform brain tumor. J Neurochem 2008, 106:1017-1026

67. Chen YL, Jian MH, Lin CC, Kang JC, Chen SP, Lin PC, Hung PJ, Chen JR, Chang WL, Lin SZ, Harn HJ: The induction of orphan nuclear receptor Nur77 expression by n-butylenephthalide as pharmaceuticals on hepatocellular carcinoma cell therapy. Mol Pharmacol 2008, 74:1046-1058

68. Chang LF, Lin PC, Ho LI, Liu PY, Wu WC, Chiang IP, Chang HW, Lin SZ, Harn YC, Harn HJ, Chiou TW: Overexpression of the orphan receptor Nur77 and its translocation induced by $\mathrm{PCH} 4$ may inhibit malignant glioma cell growth and induce cell apoptosis. J Surg Oncol 2011, 103:442-450

69. Andey T, Patel A, Jackson T, Safe S, Singh M: 1,1-Bis (3'-indolyl)-1(p-substitutedphenyl)methane compounds inhibit lung cancer cell and tumor growth in a metastasis model. Eur J Pharm Sci 2013, 50: 227-241

70. Cloonan SM, Choi AM: Mitochondria in lung disease. J Clin Invest 2016, 126:809-820

71. Hu M, Luo Q, Alitongbieke G, Chong S, Xu C, Xie L, Chen X, Zhang D, Zhou Y, Wang Z, Ye X, Cai L, Zhang F, Chen H, Jiang F, Fang H, Yang S, Liu J, Diaz-Meco MT, Su Y, Zhou H, Moscat J, Lin X, Zhang XK: Celastrol-induced Nur77 interaction with TRAF2 
alleviates inflammation by promoting mitochondrial ubiquitination and autophagy. Mol Cell 2017, 66:141-153.e6

72. Cascao R, Fonseca JE, Moita LF: Celastrol: a spectrum of treatment opportunities in chronic diseases. Front Med (Lausanne) 2017, 4:69

73. Cheng LE, Chan FK, Cado D, Winoto A: Functional redundancy of the Nur77 and Nor-1 orphan steroid receptors in T-cell apoptosis. EMBO J 1997, 16:1865-1875
74. Crawford PA, Sadovsky Y, Woodson K, Lee SL, Milbrandt J: Adrenocortical function and regulation of the steroid 21-hydroxylase gene in NGFI-B-deficient mice. Mol Cell Biol 1995, 15: 4331-4336

75. Pei L, Castrillo A, Tontonoz P: Regulation of macrophage inflammatory gene expression by the orphan nuclear receptor Nur77. Mol Endocrinol 2006, 20:786-794 